\title{
Surgery for Prolactinomas to Date
}

\author{
Michael Buchfelder Yining Zhao Sven-Martin Schlaffer \\ Department of Neurosurgery, University of Erlangen-Nuremberg, Erlangen, Germany
}

\section{Keywords}

Prolactinoma $\cdot$ Medical treatment $\cdot$ Surgery $\cdot$ Technical advances

\begin{abstract}
While in the past surgery for prolactinomas was a competitive option to medical treatment with dopamine agonists, to date the indications for operations are restricted to only a few specific situations. However, if a patient is intolerant to medical treatment or if the drugs are not sufficiently effective in terms of lowering prolactin levels or tumor shrinkage, surgery should always be considered. In microprolactinomas, operations can achieve excellent prolactin normalization rates. In tumors difficult to treat, the combination of surgical tumor resection and long-term medical treatment supports better control of the disease. The individual indications, results, techniques, and complications of operations for prolactinomas are briefly reviewed in this paper.
\end{abstract}

(C) 2019 S. Karger AG, Basel

\section{Introduction}

Only when it was shown that medical treatment with bromocriptine reduced both hypersecretion and pituitary tumor size $[1,2]$ made it sense to assess serum pro- lactin levels in every patient with a pituitary tumor, since there was an alternative management option to operative tumor extraction. The drug reduced prolactin hypersecretion and caused tumor shrinkage, thus avoiding operations. Medical treatment with dopamine agonists competed with surgery. To date, with the availability of several other dopamine agonists such as cabergoline and quinagolide, the situation is even more pronounced. These drugs are very efficacious and have relatively few side effects $[3,4]$. Thus, medical treatment to date is considered the primary treatment of choice in most patients suffering from prolactinomas $[5,6]$. Many years ago, the role of surgery had already been questioned [7]. However, the drugs do not work perfectly in each and every patient. Moreover, the surgical results in respect to both normalization of prolactin levels and tumor control were remarkable. In addition, unequivocal side effects of medical treatment are reported. Although newer dopamine agonists have even less side effects and are more efficacious than the ones that have already been available for many years, complete disappearance of the tumor is rare [4]. Advantages of surgical treatment, the permanent remission without need of continuous medication, the availability of a histological diagnosis, and the avoidance of troublesome pregnancy complications by tumoral mass effects have been quoted [8-10]. For the above-mentioned reasons, in the most recent guidelines of the Pitu-

\section{KARGER}

(c) 2019 S. Karger AG, Basel

E-Mail karger@karger.com

www.karger.com/nen
Michael Buchfelder, MD, PhD

Professor and Chairman, Department of Neurosurgery

University of Erlangen-Nuremberg, Schwabachanlage 6

DE-91054 Erlangen (Germany)

E-Mail michael.buchfelder@uk-erlangen.de 
Fig. 1. Large macroprolactinoma in a 19-year-old patient (a) at presentation and (b) 3 months after cabergoline treatment in gadolinium-enhanced T1-weighted coronal MRI sections. A few weeks later, on continuation of medical treatment, a massive rhinorrhea with pneumatocephalus developed (c), revealed by axial CT sections, which necessitated urgent surgical repair of the CSF leak at the skull base.
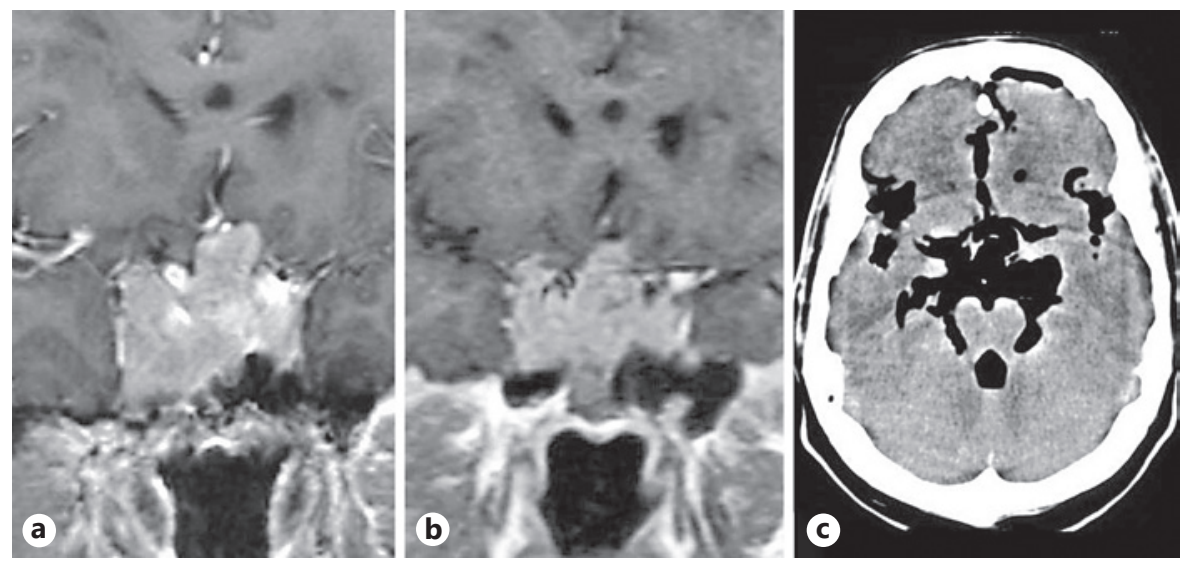
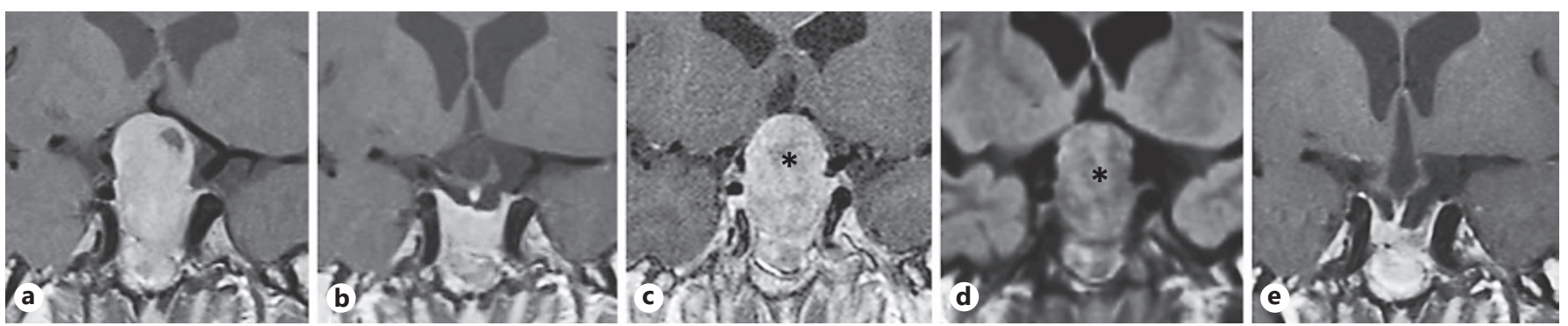

Fig. 2. Large macroprolactinoma in a 29 -year-old male patient with initial prolactin levels $>100.000 \mu \mathrm{U} / \mathrm{mL}$ (a) coronal T1 MRI + gadolinium). He was treated with cabergoline up to $6 \mathrm{mg} /$ week for 2.5 months. Prolactin levels normalized, and impressive tumor shrinkage occurred, as shown in the coronal T1-weighted MRI sec- tions with gadolinium (b). However, 6 months later, a sudden deterioration of vision occurred, caused by pituitary apoplexy (c; T1 MRI + gadolinium and d T2 FLAIR). Asterisks mark intratumoral inhomogeneities as an expression of pituitary apoplexy. The mass lesion was subsequently resected by surgery $(\mathbf{e})$. itary Society and the Endocrine Society on the treatment of prolactinomas, there is still a place for surgery $[5,11]$. Thus, the matter of the ideal candidate with a prolactinoma for surgical treatment still remains a matter of controversy.

\section{Indications for Surgery}

Despite all controversies and discussions, intolerance and insufficient responses of prolactin hypersecretion and the space-occupying lesion remain classical indications for surgery in prolactinomas. Another indication is based on side effects of prolactinoma therapy by dopamine agonists, such as cerebrospinal fluid (CSF) leaks caused by medically induced tumor shrinkage (Fig. 1). This is a more frequent problem than generally estimated, not only represented by individual case reports [1216]. Often, discontinuation of the drugs, which is in gen- eral associated with a re-expansion of the tumor, cannot solve the problem. In these situations, tumor resection and proper reconstruction of the skull base are absolutely required. Likewise, intratumoral hemorrhage, clinically presenting with "pituitary apoplexy," might require surgery if the lesion re-expands dramatically (Fig. 2). Dopamine agonist treatment seems to be a factor that can even induce pituitary apoplexy [17-19]. There was a considerable uncertainty after reports of valvular cardiac disease in patients who had been exposed to high cumulative doses of cabergoline [20] until evidence revealed that the doses used for treatment of prolactinomas are generally not high enough to cause the problem [21]. Moreover, in larger tumors, surgical volume reduction before pregnancy is advisable $[5,6]$. Many cystic tumors do not shrink sufficiently on medical treatments but can be perfectly evacuated surgically. The patient's choice to rather undergo surgery than long-term medical therapy is a relative indication for an operation. The better the 
surgical results in a center and the fewer the complications, the wider will be the range of potential surgical candidates. A recent contemporary analysis shows that the indications for surgery in one center may change during time [10]. Thus, there are few absolute and many relative indications for surgery recognized even by experts who are not in favor of surgery in all patients [6]. However, hyperprolactinemia without visible tumor in magnetic resonance imaging is not considered an indication for surgery.

\section{Surgical Techniques}

As with other pituitary tumors, most patients can be surgically treated via a transsphenoidal approach. The operating microscope and the endoscope can be used as visualization tools. In contrast to other authors, we believe that the actual surgical technique of tumor exposure and extraction does not differ much between the two methods of surgery [22-24]. With both techniques, there is the option of strictly selective tumor extraction and the "extended" adenomectomy. In the latter, one tries to preserve and remove also the thin rim of compressed pituitary tissue around the tumor, often also referred to as the "pseudocapsule." The procedure is also called extracapsular resection [25]. However, invasive tumor growth limits the possibility of complete resection of these tumors. Since some shrinkage is usually obtained even in tumors that do not respond very well to dopamine agonists, transcranial approaches, utilizing craniotomies, are even less frequently needed in prolactinomas than in other types of pituitary adenomas. In recent years, several technical developments have been made, which supported the surgeon and added to the safety of the procedures, such as intraoperative magnetic resonance imaging and neuronavigation [26].

\section{Results}

Both microscopic and entirely endoscopic series have documented very favorable results in microprolactinomas in terms of short- and even long-term normalization of prolactin levels $[8,9,27]$. Remission rates of $>90 \%$ were reported in selected small series in experienced centers [28-30]. The results of these individual series are absolutely comparable to normalization rates observed after medical treatments, so that surgery has been proposed as alternative treatment $[10,29]$. As with acro- megaly, surgical success in prolactinomas depends on the initial magnitude of prolactin oversecretion and potential invasion of the tumor into the cavernous sinus [31]. The higher the initial prolactin level ( $>200 \mathrm{ng} / \mathrm{mL})$ and the more pronounced the extension into the surrounding structures (especially laterally into the cavernous sinus), the worse is the probability of initial surgical normalization [32]. In a compilation of published series, the initial normalization rates were $83 \%$ in microprolactinomas [32] and $45.1 \%$ in macroprolactinomas [33]. Moreover, the rate of postoperative pregnancies is absolutely convincing [8]. The results seem to be even more favorable in tumors $>4 \mathrm{~mm}$, and one main predictive factor for a surgical failure is the previous exposure to dopamine agonists [34]. However, the structural, intratumoral changes induced by medical treatment vary from patient to patient [35]. If a more fibrous consistency of the tumor results, which cannot be predicted, it seems that the selectivity of adenomectomy suffers, and the patients are more likely to develop impairment of pituitary function. However, in macroprolactinomas, the normalization rates of prolactin levels are much lower. In these, the indications are mainly based on tumor control and thus, the normalization of serum prolactin levels should not be used as the main criterion of surgical success. Factors less intensively assessed, since much more difficult to measure, are recovery of vision, closure of CSF leaks, and uneventful pregnancies in female patients with large tumors. The present data from the medical literature support that a tumor volume reduction performed by surgery and additional dopamine agonist treatment results in a much more pronounced reduction of prolactin levels as compared to monotherapy in difficult-to-treat, large tumors [36]. Thus, tumor control is more easily achieved with combined treatment [37]. The high initial success rate of pure surgical intervention in prolactinomas is impeded by recurrences after initial remission. The reported average rate of these is close to $20 \%$ in 5 years, especially in macroprolactinomas, and is thus higher than the recurrence rate observed for acromegaly [38].

\section{Complications}

Due to the standardization of surgical techniques, experience, and technical developments, the occurrence of complications has been reduced to a minimum in specialized centers with surgeons dedicated to pituitary operations [24]. Although severe complications such as 
vascular arterial injuries, CSF leaks, and hypopituitarism may occur, the vast majority of patients tolerate particularly transsphenoidal surgery very well, and the in-hospital stay is short. Just as with the remission rate of hyperprolactinemia, there is some dependency on the experience of the surgeon with the procedure and the case load of the center with the individual and cumulative complication rate. These are inversely related [30, $39,40]$. If a surgeon focuses on this type of operations in one center, it seems that the results become more favorable.

\section{Conclusions}

To date, surgery is no more the standard primary option of treatment in prolactinomas. However, if treatment with dopamine agonists fails or is badly tolerated, one should not forget that there is still the operative option. The morbidity of an operation is low in experienced centers, and there have been many technical advances since the initial establishment of transsphenoidal surgery. However, the indications for surgical treatment of prolactinomas varied over time, from center to center, and may be changed under the influence of new published data in the future.

\section{References}

1 Landolt AM, Wüthrich R, Fellmann H. Regression of pituitary prolactinoma after treatment with bromocriptine. Lancet. 1979 May; 1(8125):1082-3.

2 McGregor AM, Scanlon MF, Hall K, Cook $\mathrm{DB}$, Hall R. Reduction in size of a pituitary tumor by bromocriptine therapy. N Engl J Med. 1979 Feb;300(6):291-3.

3 Biller BM, Colao A, Petersenn S, Bonert VS, Boscaro M. Prolactinomas, Cushing's disease and acromegaly: debating the role of medical therapy for secretory pituitary adenomas. BMC Endocr Disord. 2010 May;10(1):10.

4 Colao A, Pivonello R, Di Somma C, Savastano S, Grasso LF, Lombardi G. Medical therapy of pituitary adenomas: effects on tumor shrinkage. Rev Endocr Metab Disord. 2009 Jun; 10(2):111-23.

5 Casanueva FF, Molitch ME, Schlechte JA, Abs $\mathrm{R}$, Bonert V, Bronstein MD, et al. Guidelines of the Pituitary Society for the diagnosis and management of prolactinomas. Clin Endocrinol (Oxf). 2006 Aug;65(2):265-73.

6 Klibanski A. Clinical practice. Prolactinomas. N Engl J Med. 2010 Apr;362(13):1219-26.

7 Spark RF, Baker R, Bienfang DC, Bergland R. Bromocriptine reduces pituitary tumor size and hypersection. Requiem for pituitary surgery? JAMA. 1982 Jan;247(3):311-6.

8 Fahlbusch R, Buchfelder M. Present status of neurosurgery in the treatment of prolactinomas. Neurosurg Rev. 1985;8(3-4):195205.

9 Gillam MP, Molitch ME, Lombardi G, Colao A. Advances in the treatment of prolactinomas. Endocr Rev. 2006 Aug;27(5):485534.

10 Kreutzer J, Buslei R, Wallaschofski H, Hofmann B, Nimsky C, Fahlbusch R, et al. Operative treatment of prolactinomas: indications and results in a current consecutive series of 212 patients. Eur J Endocrinol. 2008 Jan;158(1):11-8.
11 Melmed S, Casanueva FF, Hoffman AR, Kleinberg DL, Montori VM, Schlechte JA, et al.; Endocrine Society. Diagnosis and treatment of hyperprolactinemia: an Endocrine Society clinical practice guideline. J Clin Endocrinol Metab. 2011 Feb;96(2):273-88.

12 de Lacy P, Benjamin S, Dixon R, Stephens JW, Redfern R, Price DE. Is surgical intervention frequently required for medically managed macroprolactinomas? A study of spontaneous cerebrospinal fluid rhinorrhea. Surg Neurol. 2009 Nov;72(5):461-3; discussion 463.

13 Honegger JB, Psaras T, Petrick M, Beuschlein F, Reincke M. Spontaneous cerebrospinal fluid rhinorrhea in untreated macroprolactinoma-an indication for primary surgical therapy. Zentralbl Neurochir. 2006 Aug;67(3): 149-54.

14 Lam G, Mehta V, Zada G. Spontaneous and medically induced cerebrospinal fluid leakage in the setting of pituitary adenomas: review of the literature. Neurosurg Focus. 2012 Jun; 32(6):E2.

15 Leong KS, Foy PM, Swift AC, Atkin SL, Hadden DR, MacFarlane IA. CSF rhinorrhoea following treatment with dopamine agonists for massive invasive prolactinomas. Clin Endocrinol (Oxf). 2000 Jan;52(1):43-9.

16 Česák T, Poczos P, Adamkov J, Náhlovský J, Kašparová $\mathrm{P}$, Gabalec $\mathrm{F}$, et al. Medically induced CSF rhinorrhea following treatment of macroprolactinoma: case series and literature review. Pituitary. 2018 Dec;21(6):561-70.

17 Ghadirian H, Shirani M, Ghazi-Mirsaeed S, Mohebi S, Alimohamadi M. Pituitary Apoplexy during Treatment of Prolactinoma with Cabergoline. Asian J Neurosurg. 2018 JanMar;13(1):93-5.

18 Nawar RN, AbdelMannan D, Selman WR, Arafah BM. Pituitary tumor apoplexy: a review. J Intensive Care Med. 2008 Mar-Apr; 23(2):75-90.
19 Sarwar KN, Huda MS, Van de Velde V, Hopkins L, Luck S, Preston R, et al. The prevalence and natural history of pituitary hemorrhage in prolactinoma. J Clin Endocrinol Metab. 2013 Jun;98(6):2362-7.

20 Zanettini R, Antonini A, Gatto G, Gentile R, Tesei S, Pezzoli G. Valvular heart disease and the use of dopamine agonists for Parkinson's disease. N Engl J Med. 2007 Jan;356(1):39-46.

21 Valassi E, Klibanski A, Biller BM. Clinical Review\#: potential cardiac valve effects of dopamine agonists in hyperprolactinemia. J Clin Endocrinol Metab. 2010 Mar;95(3):1025-33.

22 Mamelak AN. Pro: endoscopic endonasal transsphenoidal pituitary surgery is superior to microscope-based transsphenoidal surgery. Endocrine. 2014 Nov;47(2):409-14.

23 Mortini P. Cons: endoscopic endonasal transsphenoidal pituitary surgery is not superior to microscopic transsphenoidal surgery for pituitary adenomas. Endocrine. 2014 Nov; 47(2):415-20.

24 Mortini P, Barzaghi LR, Albano L, Panni P, Losa M. Microsurgical therapy of pituitary adenomas. Endocrine. 2018 Jan;59(1):72-81.

25 Taylor DG, Jane JA Jr, Oldfield EH. Resection of pituitary macroadenomas via the pseudocapsule along the posterior tumor margin: a cohort study and technical note. J Neurosurg. 2018 Feb;128(2):422-8.

26 Buchfelder M, Zhao Y, Schlaffer SM. Advances in pituitary surgery. Curr Opinion Endocr Metab Res. 2018;1:51-6.

27 Mortini P, Losa M, Barzaghi R, Boari N, Giovanelli M. Results of transsphenoidal surgery in a large series of patients with pituitary adenoma. Neurosurgery. 2005 Jun;56(6): 1222-33; discussion 1233.

28 Amar AP, Couldwell WT, Chen JC, Weiss $\mathrm{MH}$. Predictive value of serum prolactin levels measured immediately after transsphenoidal surgery. J Neurosurg. 2002 Aug;97(2): 307-14. 
29 Babey M, Sahli R, Vajtai I, Andres RH, Seiler RW. Pituitary surgery for small prolactinomas as an alternative to treatment with dopamine agonists. Pituitary. 2011 Sep;14(3):22230.

30 Honegger J, Grimm F. The experience with transsphenoidal surgery and its importance to outcomes. Pituitary. 2018 Oct;21(5):54555.

31 Jane JA Jr, Starke RM, Elzoghby MA, Reames DL, Payne SC, Thorner MO, et al. Endoscopic transsphenoidal surgery for acromegaly: remission using modern criteria, complications, and predictors of outcome. J Clin Endocrinol Metab. 2011 Sep;96(9):2732-40.

32 Tampourlou M, Trifanescu R, Paluzzi A, Ahmed SK, Karavitaki N. THERAPY OF ENDOCRINE DISEASE: Surgery in microprolactinomas: effectiveness and risks based on contemporary literature. Eur J Endocrinol. 2016 Sep;175(3):R89-96.
33 Akin S, Isikay I, Soylemezoglu F, Yucel T, Gurlek A, Berker M. Reasons and results of endoscopic surgery for prolactinomas: 142 surgical cases. Acta Neurochir (Wien). 2016 May;158(5):933-42.

34 Tamasauskas A, Sinkunas K, Bunevicius A, Radziunas A, Skiriute D, Deltuva VP. Transsphenoidal surgery for microprolactinomas in women: results and prognosis. Acta Neurochir (Wien). 2012 Oct;154(10):1889-93.

35 Menucci M, Quiñones-Hinojosa A, Burger P, Salvatori R. Effect of dopaminergic drug treatment on surgical findings in prolactinomas. Pituitary. 2011 Mar;14(1):68-74.

36 Primeau V, Raftopoulos C, Maiter D. Outcomes of transsphenoidal surgery in prolactinomas: improvement of hormonal control in dopamine agonist-resistant patients. Eur J Endocrinol. 2012 May;166(5):779-86.
37 Vroonen L, Jaffrain-Rea ML, Petrossians P, Tamagno G, Chanson P, Vilar L, et al. Prolactinomas resistant to standard doses of cabergoline: a multicenter study of 92 patients. Eur J Endocrinol. 2012 Nov; 167(5):651-62.

38 Roelfsema F, Biermasz NR, Pereira AM. Clinical factors involved in the recurrence of pituitary adenomas after surgical remission: a structured review and meta-analysis. Pituitary. 2012 Mar;15(1):71-83.

39 Barker FG 2nd, Klibanski A, Swearingen B. Transsphenoidal surgery for pituitary tumors in the United States, 1996-2000: mortality, morbidity, and the effects of hospital and surgeon volume. J Clin Endocrinol Metab. 2003 Oct;88(10):4709-19.

40 Ciric I, Ragin A, Baumgartner C, Pierce D. Complications of transsphenoidal surgery: results of a national survey, review of the literature, and personal experience. Neurosurgery. 1997 Feb;40(2):225-36; discussion 236-7. 